\title{
Kinetics of Magnetic Ageing of 2\%Si Non-oriented Grain Electrical Steel
}

\author{
José Rogério de Oliveira Júnior ${ }^{a}$, Renata Aparecida Monteiro ${ }^{b}$, Sebastião da Costa Paolinelli \\ André Barros Cota ${ }^{c *}$ \\ ${ }^{a}$ Research Department, Aperam South America, Timóteo, MG, Brazil \\ ${ }^{b}$ REDEMAT, Universidade Federal de Ouro Preto, Ouro Preto, MG, Brazil \\ ${ }^{c}$ Department of Physics, Universidade Federal de Ouro Preto, Ouro Preto, MG, Brazil
}

Received: June 12, 2017; Revised: August 28, 2017; Accepted: September 17, 2017

\begin{abstract}
The effect of carbon content on the magnetic ageing index and Vickers hardness evolution on annealed samples of $2 \% \mathrm{Si}$ non-oriented grain electrical steel was studied. Samples with 40 and $60 \mathrm{ppm}$ carbon content were subjected at ageing temperatures of 200 and $225^{\circ} \mathrm{C}$, respectively. During the ageing treatment, the cycle was interrupted on several time intervals in order to obtain the core loss and to determine Vickers hardness. The precipitates were characterized using scanning electron microscope (SEM). Using the software MatCalc, computer simulations of $\varepsilon$-carbide precipitation were performed and compared with experimental data from literature. The results for both carbon contents showed that the maximum hardness value was achieved in shorter time than that to achieve the maximum magnetic ageing, indicating that the critical size of precipitates more harmful to the magnetic properties is larger than the ones that maximize the hardness.
\end{abstract}

Keywords: non-oriented electrical steel, magnetic ageing index, Vickers hardness, simulation

\section{Introduction}

Non-oriented grain electrical steels (NOG) are soft magnetic materials used as a core of electrical machines. During the operation, the cores of alternating current motors, for example, are subjected to oscillating and rotating magnetic fields. During each magnetic flux inversion there is dissipation of heat associated with the core loss of the steel. The consequent heating up could promote the precipitation of fine second-phase particles (iron carbides), hindering the domain wall motion and increasing the magnetic core loss $\mathbf{s}^{1,2}$. Then, during the service life of the motors, generators or transformers, a deterioration in efficiency may occur, associated with the increase on magnetic loss. This phenomenon is called magnetic ageing ${ }^{2,3}$.

This dissipated energy due to magnetic loss has a hysteretic component that is much sensitive to the presence of these precipitates. The remaining two portions of the magnetic losses, namely the anomalous loss and the Foucault loss, are less influenced by the precipitation ${ }^{1,4}$.

The size, morphology, and distribution of the carbide phases depend on magnetic ageing temperature and the carbon content of the steel. It has been observed the intragranular precipitation of $\varepsilon$-carbide (transition carbide) at temperatures below $250^{\circ} \mathrm{C}$, with the approximate composition $\mathrm{Fe}_{2.4} \mathrm{C}$ and hexagonal crystal structure. The large increase in magnetic loss that accompanies transition carbide precipitation achieves a peak at specific aging temperatures depending on the carbon content of the steel ${ }^{5,6}$. It have been reported that the $\varepsilon$-carbides formed in the matrix have a precipitation predominantly at dislocations ${ }^{7}$ and they are anisotropic in shape with morphology of rods or discs ${ }^{6,8}$. Michal et at. ${ }^{5}$ have reported that the carbide particles are more harmful to the magnetic domain wall movement when their mean size is in the range of $0.5-1.5 \mu \mathrm{m}$, depending on the carbon content. After, Oliveira et al. ${ }^{6}$ have shown that the maximum increase on core loss was achieved for an average size of $\varepsilon$-carbides of 1.1 and $1.3 \mu \mathrm{m}$, for steels containing $2 \% \mathrm{Si}$, and 32 and $46 \mathrm{ppm}$ carbon contents respectively.

The effects of iron-carbides precipitation on the mechanical properties are different of those normally observed on the magnetic properties. The size, nature and the distribution of the particles must act on the domain wall and the dislocation motion by different ways ${ }^{8-10}$.

It must be pointed out that low aging susceptibility is an important requirement in the case of steels for magnetic applications, and the magnetic ageing index (AI) is used to describe the relative variation in magnetic loss due to the ageing, according to the following equation:

$$
A I=\frac{\left(W_{\text {after }}-W_{\text {before }}\right)}{W_{\text {before }}} 100
$$

where, $\mathrm{W}_{\text {before }}$ is the magnetic loss before ageing treatment and $\mathrm{W}_{\text {after }}$ is the magnetic loss after ageing treatment. The NBR and ASTM standards define that the ageing index must be lower than $5 \%$ for the non-oriented electrical steels and 
suggest specific test cycles to evaluate $i^{11,12}$. According Merz ${ }^{13}$ for a given chemical composition, there is a temperature which leads a precipitation of iron-carbides more harmful to the magnetic properties, this temperature is called as critical ageing temperature (A.T.).

For a better understanding of the effects of iron-carbides precipitation on the magnetic ageing and mechanical properties of steel, it is essential to understand its precipitation kinetics. In this work, the effects of the carbon content and carbide mean size on magnetic losses and Vickers hardness as a function of the time in $2 \% \mathrm{Si}$ non-oriented grain steel were studied. To simulated the precipitation kinetics the software package MatCalc ${ }^{14}$ was used.

\section{Experimental}

Two sets of annealed samples with $300 \times 30 \times 0.54 \mathrm{~mm}$ of $2 \% \mathrm{Si}$ non-oriented grain electrical steel were subjected to heat treatment at the ageing temperature for periods from $5 \mathrm{~min}$ to $5400 \mathrm{~min}$ (90h). The chemical composition and the ageing temperatures determined from Oliveira et al. ${ }^{6}$ results are shown in the Table 1.

Table 1. Chemical composition in weight $\%$ and the critical ageing temperature (A.T).

\begin{tabular}{ccccccc}
\hline Steel & $\mathrm{C}$ & $\mathrm{Si}$ & $\mathrm{Mn}$ & $\mathrm{Al}$ & $\mathrm{N} 2$ & $\begin{array}{c}\text { A.T } \\
\left({ }^{\circ} \mathrm{C}\right)\end{array}$ \\
\hline 1 & $0.004(40 \mathrm{ppm})$ & 2.0 & 0.42 & 0.0027 & 0.0038 & 200 \\
2 & $0.006(60 \mathrm{ppm})$ & 2.0 & 0.42 & 0.0027 & 0.0038 & 225 \\
\hline
\end{tabular}

In order to evaluate the magnetic ageing index along the time, in each interruption of the cycle, the core losses of the samples were measured in the rolling direction using the single strip tester at $1.0 \mathrm{~T}$ and $50 \mathrm{~Hz}$. In addition, selected samples were analyzed using scanning electron microscopy (SEM) to evaluate carbides distribution. The mechanical properties were evaluated through Vickers hardness with $1 \mathrm{~kg}$ load in each interruption of cycle.

\subsection{Simulation Method}

The software package MatCalc ${ }^{14}$ uses the classical nucleation theory along with Onsager's extremum principle for simulating precipitate evolution. It has a numerical model to classify precipitates of same radius and composition nucleated in different time intervals. Precipitates of equal size and chemical composition are grouped into classes, for each of which the evolution in size and composition is calculated according to the rate equations derived from the thermodynamic extremum principle. Nucleation of new precipitates is taken into account in each time step based on a multicomponent extension of classical nucleation theory ${ }^{15}$. Accordingly, the transient nucleation rate $\mathrm{J}$ defines the number of new nuclei created in the time step $\Delta \mathrm{t}$ as $\mathrm{J} \Delta \mathrm{t}$, and $\mathrm{J}$ is given by

$$
J=N_{0} Z \beta^{*} \exp \left(-\frac{G^{*}}{k T}\right) \exp \left(-\frac{\tau}{t}\right)
$$

where $N_{0}$ represents the total number of potential nucleation sites, $k$ is the Boltzmann constant, $T$ is the temperature, $Z$ is the Zeldovich factor ${ }^{16}, \beta^{*}$ is the atomic attachment rate $^{17}$, $\tau=1 /\left(2 \beta^{*} Z^{2}\right)$ is the incubation time and $G^{*}$ is the critical nucleation energy given by

$$
G^{*}=\frac{16 \pi}{3} \frac{\gamma^{3}}{\left(\Delta G_{v o l}-\Delta G_{s}\right)^{2}}
$$

with the interfacial energy $\gamma$, the volume free energy change $\Delta G_{v o l}$ and the misfit strain energy change $\Delta G_{s} \cdot \gamma$ and $\Delta G_{v o l}$ and their composition and temperature dependences are evaluated using the Gibbs energy database. Both quantities are most essential for achieving reliable calculation of nucleation rates for precipitation kinetics simulations. All required quantities can be calculated from appropriate analytical expressions using the Gibbs energy and mobility databases. Detailed expressions for all nucleation related quantities are summarized by Janssens et al. ${ }^{15}$. The number of potential nucleation sites $N_{0}$ occurring in Eq. (1) is dependent on the choice whether nucleation is homogeneous or heterogeneous (nucleation on dislocations, grain boundaries (GB), subgrain boundaries (SGB), grain boundary edges or grain boundary corners). Detailed expressions for calculation of nucleation sites in microstructures can be found elsewhere ${ }^{18}$.

For the present simulations, the thermo-kinetic software MatCalc $^{14}$ (version 5.62) and the corresponding databases mc_fe_v2.057.tdb and mc_sample_fe2.ddb were used.

\section{Results}

The changes in the magnetic ageing index (AI) as a function of time at $200^{\circ} \mathrm{C}$ and $225^{\circ} \mathrm{C}$ for samples with $40 \mathrm{ppm}$ and $60 \mathrm{ppm}$ carbon contents respectively are shown in Figure 1. It can be observed that magnetic ageing index reaches the highest value $(59 \%)$ at $30 \mathrm{~h}$ of ageing treatment for sample with $60 \mathrm{ppm}$ carbon, and it exceeds $5 \%$ after $1.4 \mathrm{~h}$ of ageing treatment at $225^{\circ} \mathrm{C}$. When the carbon content decreases to $40 \mathrm{ppm}$ it was necessary $3.1 \mathrm{~h}$ of ageing treatment at $200^{\circ} \mathrm{C}$ to achieve AI 5\%, and $66 \mathrm{~h}$ to achieve the highest AI (41\%). The behaviour of the ageing index curves of both steels was similar, outlining a tendency to the stabilization, which takes place more quickly with the increasing of the carbon content. The magnetic ageing process was much faster for a higher carbon content with $60 \mathrm{ppm}$ carbon aged at $225^{\circ} \mathrm{C}$ than for a lower one with $40 \mathrm{ppm}$ carbon aged at $200^{\circ} \mathrm{C}$. 


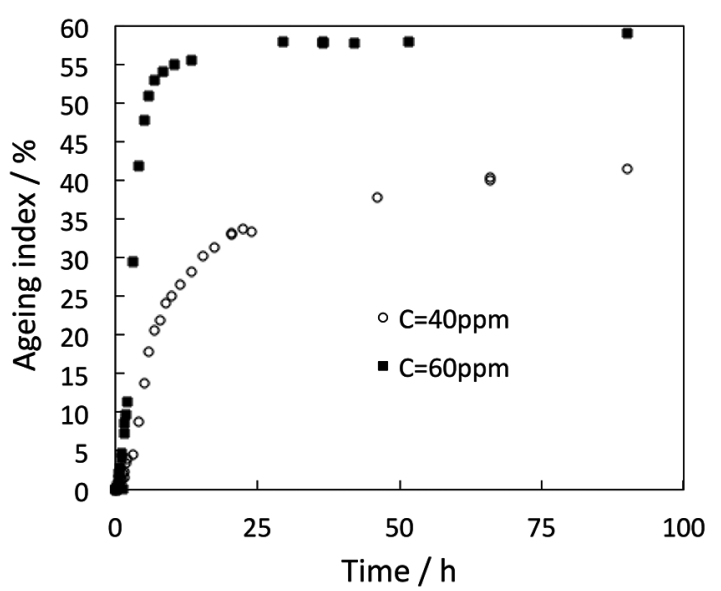

Figure 1. Behaviour of the ageing index as a function of time for samples with $40 \mathrm{ppm}$ and $60 \mathrm{ppm} \mathrm{C}$ aged at 200 and $225^{\circ} \mathrm{C}$, respectively.

The results of the Vickers hardness as a function of time are presented in Figure 2. Both samples with 40 and $60 \mathrm{ppm}$ have shown a slight increase in the hardness up to $1.5 \mathrm{~h}$ of ageing treatment. After that, it was observed hardness peaks around $1.2 \mathrm{~h}$ and $1.5 \mathrm{~h}$ of ageing treatment, which represent a $33 \%$ and $27 \%$ increase in comparison to the non-aged samples, for the samples with 60 and 40ppm C, respectively. After pass through this point, the hardness decreased.

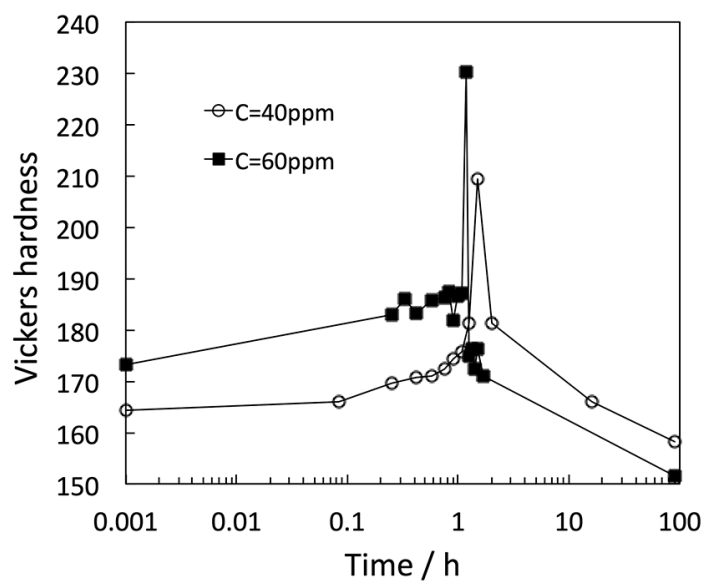

Figure 2. Vickers hardness evolution ( $1 \mathrm{~kg}$ load) of the samples with 40 and $60 \mathrm{ppm} \mathrm{C}$ aged at 200 and $225^{\circ} \mathrm{C}$, respectively.

The microstructural analysis by SEM for each sample taken at selected ageing times are shown in the Figure 3. The average grain size of recrystallized ferrite was $57 \mu \mathrm{m}$. For samples without ageing treatment a very few carbides were detected (Figure $3 \mathrm{a}$ and Figure $3 \mathrm{~d}$ ). In Figure $3 \mathrm{~b}$ (ageing treatment time of 1.2h) and Figure $3 \mathrm{e}$ (ageing time of 1.5h) can be observed a thin distribution of carbides in the samples and these ageing times are the values for which the Vickers hardness reach the highest values. It can been seen a high volume fraction of iron-carbides (Figure 3c and Figure 3f) after ageing for $90 \mathrm{~h}$, and the carbide mean size in sample with $40 \mathrm{ppm}$ is smaller than in sample with 60ppm.

\section{Discussion}

The precipitation kinetics of $\varepsilon$-carbides $\left(\mathrm{Fe}_{2.4} \mathrm{C}\right)$ during ageing treatment was evaluated using the software MatCalc. First, the computer simulations of $\varepsilon$-carbide precipitation were performed considering the steel with $32 \mathrm{ppm} \mathrm{C}$ and ageing temperature of $180^{\circ} \mathrm{C}$, and compared with experimental results from Oliveira et al. ${ }^{6}$. These authors measured the mean size of precipitates for steel with $32 \mathrm{ppm} \mathrm{C}$ and aged at $180^{\circ} \mathrm{C}$, being reported the maximum dimension since carbide particles are anisotropic in shape.

The microstructures showed that the $\varepsilon$-carbide precipitation happens intragranulary and its nucleation may occur at dislocations, dependent on chemical composition and ageing temperature.

The Figure 4 shows the mean size of $\varepsilon$-carbides as a function of time obtained from simulation and experimental data ${ }^{6}$. The simulation gave good agreement with the experimental data. In the simulation, the nucleus composition model was para-equilibrium, i.e., the nucleus is assumed to have the same composition in terms of substitutional elements as the matrix from which it forms, and only the carbon is partitioned between the two phases. The dislocation density was assumed to be $3 \times 10^{9} \mathrm{~m}^{-2} 19$ for precipitation occurring from ferrite, and since carbide particles are anisotropic in shape, it was assumed that the carbides have rods morphology, and it was used in the simulation a shape factor equal to 12 .

These simulation parameters were used to determine the mean $\varepsilon$-carbides size and the carbide mass fraction as a function of time for samples with $40 \mathrm{ppm} \mathrm{C}$ aged at $200^{\circ} \mathrm{C}$ and $60 \mathrm{ppm}$ aged at $225^{\circ} \mathrm{C}$ (Figure 5 and Figure 6), including the simulation results for sample with $32 \mathrm{ppm}$ aged at $180^{\circ} \mathrm{C}$.

The Figure 1 shows that the lower carbon steel (40ppm C) developed a maximum magnetic ageing index after ageing at $200^{\circ} \mathrm{C}$ in $66 \mathrm{~h}$ and the higher carbon steel developed a maximum ageing index after ageing at $225^{\circ} \mathrm{C}$ in $30 \mathrm{~h}$. These results are due to the combined influence of particle size and volume fraction on the coercive force and the hysteretic loss, which is a major component in the total magnetic loss ${ }^{1,10}$. These maximum magnetic ageing indexes were observed when the mean $\varepsilon$-carbide size was $1.13 \mu \mathrm{m}$ for sample with $40 \mathrm{ppm} \mathrm{C}$ and $1.30 \mu \mathrm{m}$ for sample with 60ppm C (Figure 5). Several investigators have noted that carbides with mean size in the range $0.5-1.5 \mu \mathrm{m}$ are more harmful to the magnetic domain wall movement ${ }^{5,6}$, and Oliveira et al. ${ }^{6}$ have shown that for steels with $2 \% \mathrm{Si}$ the highest magnetic ageing index was achieved for an average size of $\varepsilon$-carbides of $1.1 \mu \mathrm{m}$ and $1.3 \mu \mathrm{m}$ for samples containing 32 and 46ppm carbon, respectively. 

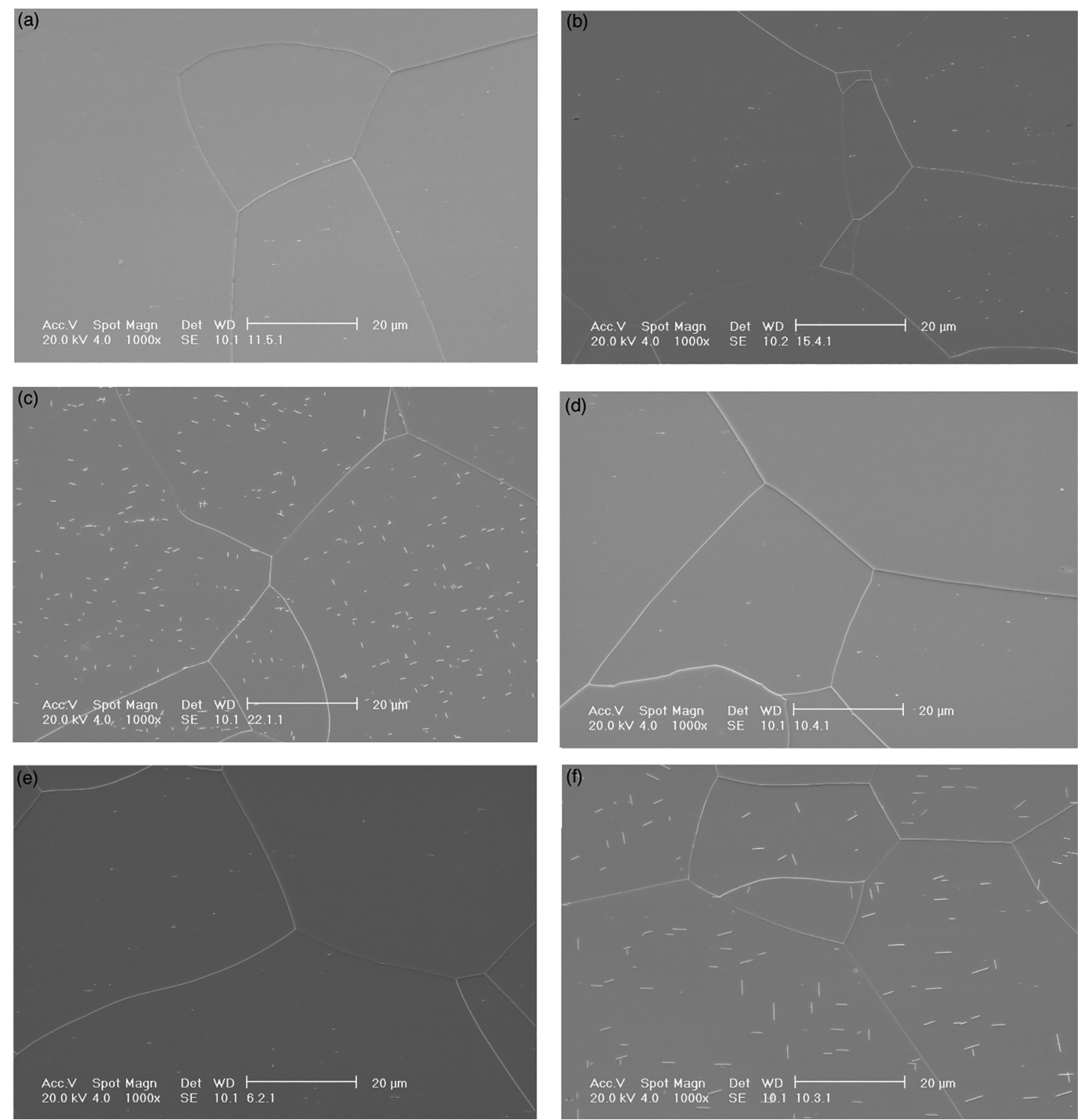

Figure 3. Iron-carbides evolution in the samples with $40 \mathrm{ppm} \mathrm{C}$ aged: a) $0 \mathrm{~h}, \mathrm{~b}) 1.2 \mathrm{~h}$ c) $90 \mathrm{~h}$ at $200^{\circ} \mathrm{C}$, and in samples with $60 \mathrm{ppm}$ aged: d) $0 \mathrm{~h}$, e) $1.5 \mathrm{~h}$, f) $90 \mathrm{~h}$ at $225^{\circ} \mathrm{C}$.

In materials such as iron, particles with a diameter of about $1 \mu \mathrm{m}$ or larger will have a spike domains attached to them and tend to anchor the domain walls. On the other hand, smaller particles also tend to impede the wall motion, reducing the energy of the wall. Therefore, there is a particle diameter that maximizes the pinning effect on the domain wall. This effect, according Cullity ${ }^{20}$, is more effective when the particle diameter is about equal to the wall thickness. However, associated with the peak in the coercive force, Ray et al. ${ }^{9}$ have found a particle size 4-9x higher than the ferrite domain wall size of about $1 \mu \mathrm{m}$. Although controversial, these investigations ${ }^{5,6,9}$, clarify that most effective carbide size for pinning the domain walls motion in iron is around $1 \mu \mathrm{m}$ or around $10 \mathrm{x}$ the domain wall size.
In this paper, magnetic ageing index of 5\% $(\mathrm{AI}(5 \%))$ value was adopted as the ageing threshold for ultra-low carbon electrical steel after decarburizing treatment. It can be observed that magnetic ageing index exceeds $5 \%$ after $1.4 \mathrm{~h}$ of ageing treatment at $225^{\circ} \mathrm{C}$ for sample with $60 \mathrm{ppm}$ carbon, and when the carbon content decreases to $40 \mathrm{ppm}$ it was necessary $3.1 \mathrm{~h}$ of treatment at $200^{\circ} \mathrm{C}$ to achieve $5 \%$ AI. For samples with $40 \mathrm{ppm}$ the mean carbide size and volume fraction are $0.73 \mu \mathrm{m}$ (Figure 5) and $0.018 \%(29 \%$ of the total carbide mass fraction of equilibrium) (Figure 6), respectively. For samples with 60ppm the mean carbide size increased to $0.91 \mu \mathrm{m}$ (Figure 5) and the volume fraction of carbides (Figure 6) increased to $0.033 \%$ (35.5\% of the total carbide mass fraction of equilibrium). 


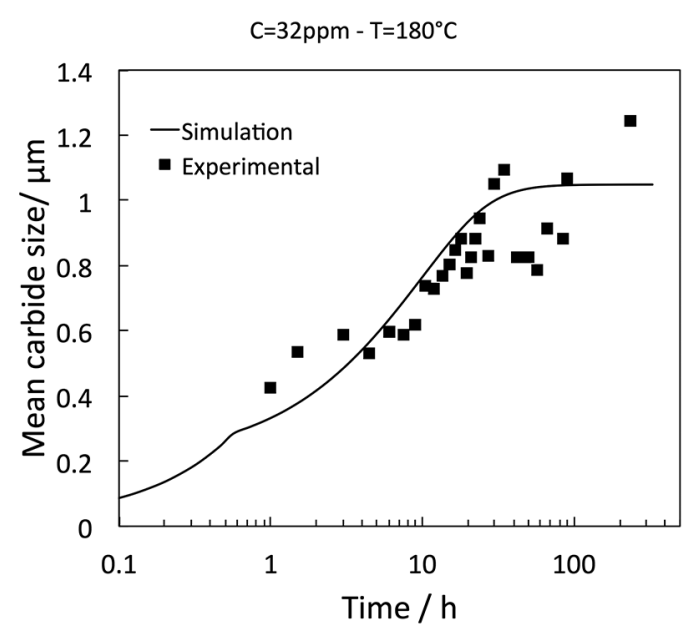

Figure 4. Fitting of experimental data of carbide mean size with time for a sample with $32 \mathrm{ppm} \mathrm{C}$ and aged at $180^{\circ} \mathrm{C}$.

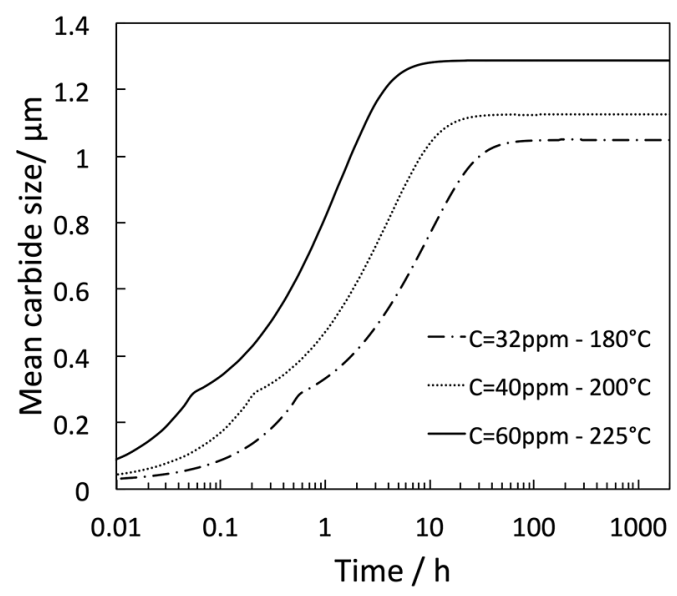

Figure 5. Carbide mean size evolution for samples with 32,40 and $60 \mathrm{ppm}$ aged at 180,200 and $225^{\circ} \mathrm{C}$, respectively.

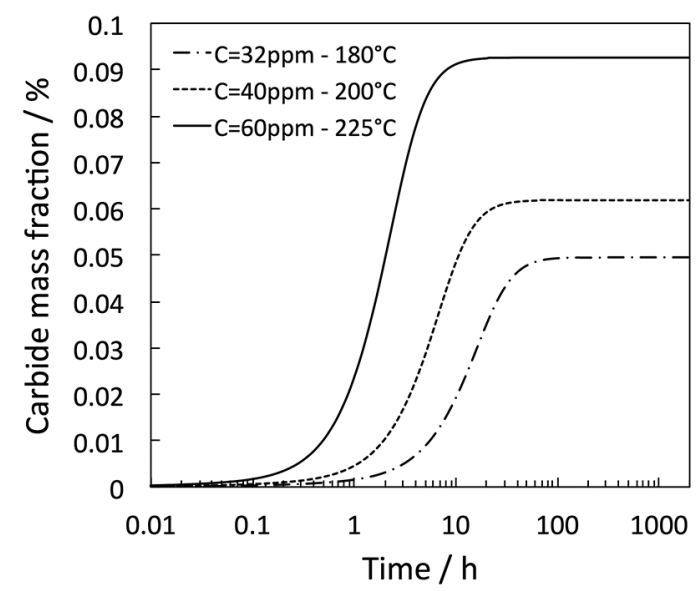

Figure 6. Carbide mass fraction evolution for samples with 32,40 and $60 \mathrm{ppm}$ aged at 180,200 and $225^{\circ} \mathrm{C}$, respectively.
Figure 7 shows the mean carbide size as a function of carbon content for the maximum ageing index (AI(max)), AI (5\%) and maximum Vickers hardness (HV(max)) determined from Figure 1, Figure 2 and Figure 5, including the experimental some data for samples containing $2 \% \mathrm{Si}$ and 32ppm C obtained elsewhere ${ }^{6}$.

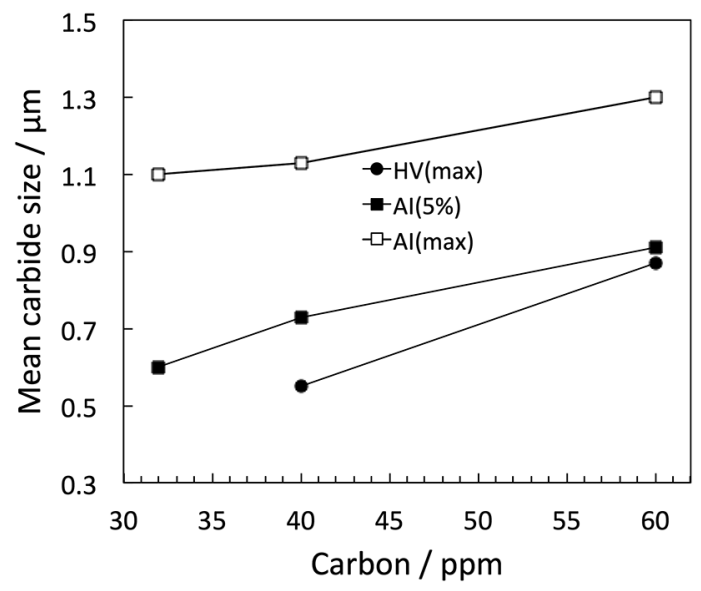

Figure 7. Mean carbide size as a function of carbon content. The experimental data for sample with $32 \mathrm{ppm} \mathrm{C}$ were obtained from Oliveira et al. ${ }^{6}$ for $\mathrm{AI}(5 \%)$ and $\mathrm{AI}(\max )$.

Figure 2 shows that during the course of the ageing treatment occurred the reduction of carbon in supersaturated solid solution in the matrix due the $\varepsilon$-carbide formation. Then, there are two phenomena occurring, which act on hardness by opposite ways: the reduction of the carbon in solid solution, which implies in hardness reduction and the carbide precipitation that can lead an increase on the hardness. The simultaneous carbon depletion and precipitation in the matrix, at the initial stages of the treatment, results in depletion/precipitation balance that leads to slight increase on the hardness.

The hardness achieves the maximum values when mean size and volume fraction of $\varepsilon$-carbides achieve the maximum restraint effect on the dislocation movement for carbon contents. Ageing peaks, as measured by Vickers hardness, are reached much earlier than the magnetic ageing peaks measured by magnetic loss, because the precipitate size leading to maximum restrain of dislocation motion is much smaller than that exerting maximum restrain of magnetic domain wall motion ${ }^{10}$.

It can be observed in the Figure 7 that the maximum hardness is achieved for mean carbide sizes smaller than the values that lead to the maximum magnetic ageing index. The results show that an increase in the carbon content from 40 to $60 \mathrm{ppm}$ leads to an increase in the mean carbide size from 0.55 to $0.87 \mu \mathrm{m}$, and to an increase in the precipitate volume fraction from 13 to $32.3 \%$, for the hardness reaches maximum values. 


\section{Conclusions}

For the $2 \% \mathrm{Si}$ non-oriented grain steel, the magnetic ageing process was much faster for a higher carbon content with $60 \mathrm{ppm}$ carbon aged at $225^{\circ} \mathrm{C}$ than for a lower one with $40 \mathrm{ppm}$ carbon aged at $200^{\circ} \mathrm{C}$. These maximum magnetic ageing indexes were observed when the mean $\varepsilon$-carbide size was $1.13 \mu \mathrm{m}$ for sample with $40 \mathrm{ppm} \mathrm{C}$ and $1.30 \mu \mathrm{m}$ for sample with $60 \mathrm{ppm} \mathrm{C}$.

The microstructures showed that the $\varepsilon$-carbide precipitation happens intragranulary and its nucleation may occur at dislocations, dependent on chemical composition and ageing temperature.

The simulations clearly demonstrated that the maximum hardness is achieved for mean carbide sizes smaller than the values that lead to the maximum magnetic ageing index. The hardness reached maximum values when the mean carbide size is $0.55 \mu \mathrm{m}$ for $40 \mathrm{ppm} \mathrm{C}$ and $0.85 \mu \mathrm{m}$ for $60 \mathrm{ppm} \mathrm{C}$.

The maximum effect on magnetic losses was achieved at longer times when the precipitates present a coarse size. This confirms that mean carbide size that maximizes the pin effect on the domain wall motion is larger than those that maximize the effect on hardness.

\section{Acknowledgment}

The authors would like to thank Aperam South America by using of its facilities and CAPES for supporting this study.

\section{References}

1. Marra KM, Alvarenga EA, Buono VTL. Magnetic aging anisotropy of a semi-processed non-oriented electrical steel. Materials Science and Engineering: A. 2005;390(1-2):423-426.

2. Ray SK, Mohanty ON. Magnetic ageing characteristics of low silicon electrical steels. Journal of Magnetism and Magnetic Materials. 1982;28(1-2):44-50.

3. Negri GMR, Sadowski N, Batistela NJ, Leite JV, Bastos JPA. Magnetic Aging Effect Losses on Electrical Steels. IEEE Transactions on Magnetics. 2016;52(5):2001104.

4. Campos MF, Emura M, Landgraf FJG. Consequences of magnetic aging for iron losses in electrical steels. Journal of Magnetism and Magnetic Materials. 2006;304(2):e593-e595.

5. Michal GM, Slane JA. The kinetics of carbide precipitation in silicon-aluminum steels. Metallurgical Transactions $A$. 1986;17(8):1288-1294.
6. Oliveira Jr JR, Paolinelli SC, Gonzalez BM, Rodrigues MV. Influência das características microestruturais sobre as propriedades magnéticas do aço silício de grão não orientado 2\%Si. In: Proceedings of the $69^{\circ}$ ABM International Annual Congress; 2014 Jul 21-25; São Paulo, SP, Brazil.

7. Ray SK, Mohanty ON. TEM Investigation of Carbide Precipitation in Low Carbon Steels Containing Silicon. Transactions of the Japan Institute of Metals. 1983;24(2):81-87.

8. Abe H. Carbide precipitation during ageing treatments. Scandinavian Journal of Metallurgy. 1984;13:226-239.

9. Ray SK, Mohanty ON. On predicting the extent of magnetic aging in electrical steels. Journal of Magnetism and Magnetic Materials. 1989;78(2):255-262.

10. Leslie WC, Rauch GC. Precipitation of carbides in low-carbon Fe-Al-C alloys. Metallurgical Transactions A. 1978;9(3):343349.

11. Associação Brasileira de Normas Técnicas (ABNT). NBR 5161 Produtos laminados planos de aço para fins elétricos - verificação das propriedades. Rio de Janeiro: ABNT; 1977. 35 p.

12. ASTM International. ASTM A340-03 - Standard Terminology of Symbols and Definitions Relating to Magnetic Testing. West Conshohocken: ASTM International; 2003. 16 p.

13. Merz H. The critical ageing temperature for electrical steel. Archiv für das Eisenhüttenwesen. 1970;41(2):159-164.

14. Kozeschnik E, Buchmayr B. MatCalc - a simulation tool for multi-component thermodynamics, diffusion and phase transformation kinetics. In: Cerjak H, Bhadeshia HKDH, eds. Mathematical Modelling of Weld Phenomena. London: London Institute of Materials; 2001. p. 349-361.

15. Janssens KGF, Raabe D, Kozeschnik E, Miodownik MA, Nestler B. Computational Materials Engineering-An Introduction to Microstructure Evolution. London: Academic Press; 2007.

16. Russell KC. Nucleation in solids: The induction and steady-state effects. Advances in Colloid and Interface Science. 1980;13(34):205-318.

17. Svoboda J, Fischer FD, Fratzl P, Kozeschnik E. Modelling of kinetics in multi-component multi-phase systems with spherical precipitates: I: Theory. Materials Science and Engineering: $A$. 2004;385(1-2):166-174.

18. Rajek HJ. Computer simulation of precipitation kinetics in solid metals and application to the complex power plant steel CB8. [Thesis]. Graz: Graz University of Technology; 2005.

19. Humphreys FJ, Hatherly M. Recrystallization and Related Annealing Phenomena. Oxford: Pergamon Press; 1996.

20. Cullity BD, Graham CD. Introduction to Magnetic Materials. 2nd ed. Piscataway: IEEE Press; 2009. 